Military Technical College

Kobry El-Kobbah, Cairo, Egypt

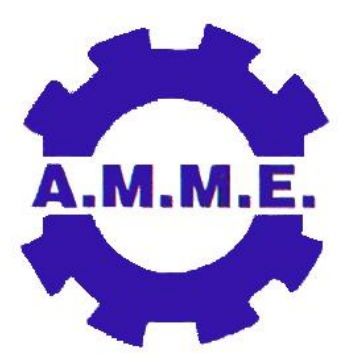

14th International Conference on Applied Mechanics and Mechanical Engineering.

\title{
Advanced Numerical and Experimental Studies of Premixed Flame Propagation Past Solid Obstructions
}

By

\author{
S.S. Ibrahim*
}

\section{Abstract:}

This paper describes recent numerical and experimental studies of the interactions between propagating premixed flame and solid obstructions. The study has been performed in a range of laboratory platforms where controlled premixed flames are set to propagate past solid obstacles and/or baffle plates strategically positioned in vented combustion chambers. Researchers have studied the effects of various parameters such as obstacle shape, blockage ratio, repeated obstacles, venting area, and combustor size where the length of the combustion chamber in the direction of the propagating flame is varied with respect to the chamber's width or diameter.

Computational approaches used in simulating propagating premixed flames range from simple ones that are numerically feasible for practical applications such as those based on Reynolds Averaged Navier Stokes (RANS) equations to complex and numerically very expensive such as Large Eddy Simulation (LES) methods. Experimentally, high speed images of the propagating flames as well pressure-time traces are widely available for a range of experimental conditions but flow field measurements are less common due to the seeding difficulty associated with such transient processes. This paper reviews also recent experiments where the flame front was imaged was imaged using laser induced fluorescence (LIF) from the hydroxyl radical.

Keywords: premixed flame propagation, burning rates, flame interaction with obstacles, LES simulations, deflagration overpressure, laser induced fluorescence 
Proceeding of the $14^{\text {th }}$ AMME Conference, 25 -27 May 2010

* Department of Aeronautical and Automotive Engineering, Loughborough University, Loughborough LE11 3TU, UK 


\section{Introduction}

Turbulent propagating premixed flames may be encountered in park ignition engines, gas turbines, industrial burners, as well as in vented gas explosions. In all these applications, the flame fronts interact with complex solid boundaries and with the turbulence generated in the medium of propagation ahead of the flame front. These interactions distort the flame structure and directly affect the propagation rate in ways that are not yet fully understood. In flame deflagrations which result from vented gas explosions, the resulting overpressure causes significant damage to the surroundings and the magnitude of the overpressure is directly affected by many factors particularly obstacle geometry and blockage ratio.

Computing the burning rate of the fuel mixture and, in the case of vented explosions, the resulting overpressure remains a considerable challenge which, when overcome, will have a positive impact on energy efficiency as well as industrial safety. The outstanding problem remains that of accounting for the turbulence-chemistry interactions. Large Eddy Simulation methods are making significant advances in this field where the transient nature of the fluid dynamics is computed adequately and where subgrid-scale models for chemical reaction are constantly improved [1-2]. Although flamelet-based models are widely used due to simplicity, better approaches based on flame surface density (FSD) are gradually implemented with separate transport equation equations being solved for the FSD [3-6].

Many different configurations were used for the experimental investigations of these issues. Earlier efforts focused on large-scale experiments [7-9] which, are impractical for detailed analysis and yielded limited data primarily in the form of pressure-time histories. More recently, laboratory-scale experiments have become the preferred method of investigation, utilising simple geometrical configurations that more easily lend themselves to complex diagnostics and subsequent validation of numerical models [10-20].

Studies have been performed using many vessels, including enclosed cylindrical vessels $[12,13]$, cylindrical vessels with turbulence inducing rings [14-16], spiral tubing [18] and circular plate obstructions [13], square vessels with wall baffles [19], and, recently, square cross section chambers with various rectangular, cylindrical and flat plate obstructions $[5,10,11]$. Although knowledge is continually expanding there are still outstanding research issues, in particular the lack of any detailed understanding of the effects of obstacles in the path of a propagating flame on the propagation rate, the flame surface density and associated flame front structures, and the resulting influence on burning rate and the turbulence-burning rate positive feedback mechanism.

An abundance of valuable data was obtained from the experimental configuration that uses a square cross section [10,11]. However, post-analysis reveals some disadvantages, primarily, an inability to produce any significant amount of turbulence in either the cold mixture upstream of the flame or in recirculation zones behind the obstacle following the flame front propagation. The large volume is likewise conducive to large processing times for practical numerical simulation. As a result, a reduction in size from 20 litres to less than 1 litre has been implemented, allowing for use of repeated obstacles to generate high levels of turbulence without the risk of deflagration to detonation transition. The small size minimises computational time required for LES, whilst broad optical access is incorporated into the design to facilitate a wide range of experimental diagnostic techniques. 
A common feature to all the studies reported so far is that the chamber's length $L$ in the direction of the propagating flame is large compared to its diameter, $D$ or the width of the its base, W. Ratios of L/D for the cylindrical chambers studied by Alexiou et al [17] and Fairweather et al [15] range, respectively from 15.4 to around 2. Green et al. [21] have recently investigated premixed flame propagation in an experimental chamber with an L/D ratio of 0.235 . The short length of this chamber leads to some interesting and, some cases, apparently controversial results regarding the nature of the flame's interaction with solid obstacles. The paper elaborates on these findings further.

Numerically, the burning rate is quantified either in terms of the turbulent burning velocity $u_{t}$ or the flame surface density, $\Sigma$. Current models for $u_{t}$ as a function of turbulence intensity alone show significant variations [22]. Flame surface density approaches, either use a full transport equation for $\Sigma$ [3-5] or apply the flamelet assumption and use an algebraic closure model as a function of a reaction progress variable [6]. The former approach still involves a significant degree of empiricism in modelling the unclosed terms [5]. The Large Eddy Simulation (LES) approach remains computationally much more expensive than Reynolds Averaged Navier Stokes (RANS) methods but is gradually gaining acceptance as a viable tool for simulating turbulent premixed [23-27] and non-premixed [28-30] flames. An excellent review of recent advances in this field is reported by Janicka and Sadiki [31].

LES computations of turbulent premixed flames based on the laminar flamelet assumption have proliferated over the last few years [23-27]. The challenge here remains to generate subgrid models for combustion that are independent of both the grid size and the filter width. Attempts toward achieving this goal are being made. This paper discusses recent efforts in this area and reviews recent experimental findings that lead to improved understanding of how premixed flame fronts interact with turbulence and solid surfaces.

\section{Experimental}

This paper focuses primarily on one experimental configuration that is representative of the various efforts performed by research groups on this topic. Complementary or controversial results from other groups are also stated with an explanation or an attempt for reconciliation where possible.

\subsection{The combustion chamber}

Figure 1 shows a schematic of the third and latest iteration of the combustion chamber that was developed over time at the University of Sydney. The vessel is square in cross-section, with internal dimensions of $50 \times 50 \mathrm{~mm}$, and an overall length of $250 \mathrm{~mm}$. The walls are constructed in two sections: an inner assembly comprised of several $5 \mathrm{~mm}$ thick bonded Perspex spacers of varying lengths used to separate a variety grids and obstacles that realise the geometrical configuration for a given experiment, and an outer a box constructed from 20 $\mathrm{mm}$ thick Perspex that encapsulates the entire inner assembly for added strength. The inner and outer assemblies are placed between a Perspex base plate and an aluminium top plate, and the entire rig is then held firmly together using draw bolts and mounted on a traverse rig.

The turbulence generating grids are constructed from aluminium and placed between the Perspex spacers. For this preliminary investigation the grids may be situated at any one of 
three 'stations' located $20 \mathrm{~mm}$ (S1), $50 \mathrm{~mm}$ (S2) and $80 \mathrm{~mm}$ (S3) downstream of the ignition point. Two separate geometries for the turbulence-generating grid have been used. Grid $A$ consists of five $4 \mathrm{~mm}$ wide strips evenly separated by six $5 \mathrm{~mm}$ wide spaces, whilst Grid $B$ is the inverse of Grid A consisting of six $5 \mathrm{~mm}$ wide strips evenly separated by five $4 \mathrm{~mm}$ wide spaces (blockage ratios of 0.4 and 0.6 respectively). A square obstruction $12 \times 12 \mathrm{~mm}$ constructed from aluminium and running the full width of the chamber is also present and placed parallel to the grids, $100 \mathrm{~mm}$ downstream of the ignition point.

Liquefied Petroleum Gas ( $88 \% \mathrm{C}_{3} \mathrm{H}_{8}, 10 \% \mathrm{C}_{3} \mathrm{H}_{6}$ and $2 \% \mathrm{C}_{4} \mathrm{H}_{10}$ by vol.) enters through a nonreturn valve in the base plate at a $\sim 20 \mathrm{~g} / \mathrm{min}$ and equivalence ratio of $\Phi=1.0$, except in cases where the effect of stoichiometry is the experimental objective. A hinged flap actuated via a pneumatic valve closes the top of the vessel during filling and is opened prior to ignition. Ignition is by the infrared output from a YAG laser focussed onto the centre of the base plate surface.

Pressure is recorded using a Keller type PR21-SR peizo-electric pressure transducer with a range of 0 - 1 Bar and a total error $<0.5 \%$ located in the base plate. Simultaneously, highspeed images (2000 fps) are recorded using a MotionScope PCI 8000 S camera. The entire experimental sequence is automated using computer software. With this design multiple, experimental configurations are easy to investigate simply by altering the number and spacing of the turbulence generating grids and obstructions. The low overpressures generated minimize detrimental shock-wave effects on laboratory equipment, whilst the small volume (0.625 litres) will allow for relatively small computation times for numerical modellers.
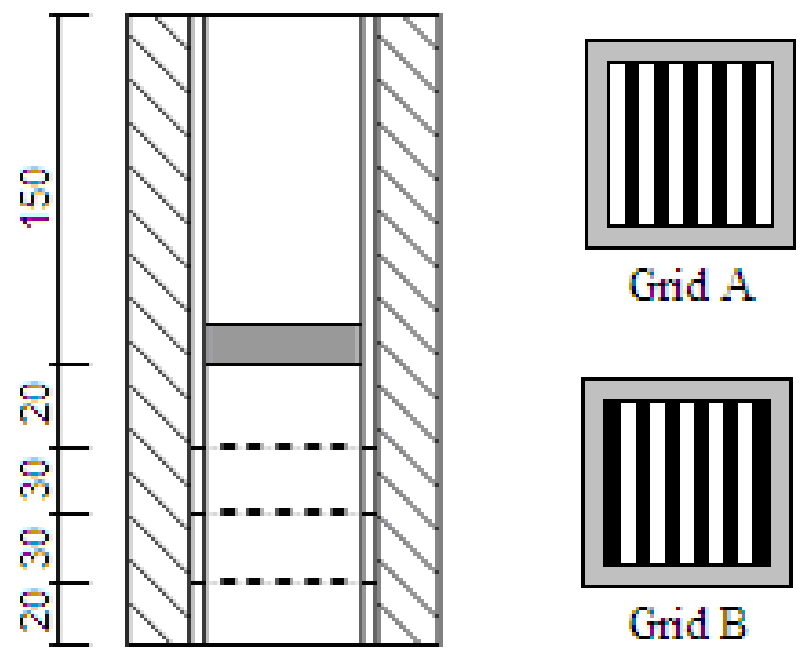

Grid B

Fig. 1 Schematic of combustion chamber at the University of Sydney.

\subsection{Overpressure at various configurations}

A large number of configurations was investigated where one, two or three grids were used as well as obstacles of various shapes and blockage ratios. Table 1 shows a list of the configurations used with (or without) an obstacle of square cross section with a blockage ratio of $40 \%$. The peak pressure obtained with each configuration is also shown. 


\begin{tabular}{|c|c|c|c|c|c|}
\hline $\begin{array}{c}\text { Config. } \\
\text { No. }\end{array}$ & S1 & S2 & S3 & Obst. & $\begin{array}{c}\text { Peak Pressure } \\
\text { (mbar) }\end{array}$ \\
\hline 1 & A & A & A & Y & 146 \\
\hline 2 & - & A & A & Y & 125 \\
\hline 3 & A & - & A & Y & 92 \\
\hline 4 & A & A & - & Y & 80 \\
\hline 5 & - & - & A & Y & 88 \\
\hline 6 & A & - & - & Y & 32 \\
\hline 7 & - & - & - & Y & 28 \\
\hline 8 & - & - & - & N & 4 \\
\hline 9 & A & B & A & Y & 172 \\
\hline 10 & B & A & A & Y & 184 \\
\hline 11 & - & B & A & Y & 145 \\
\hline 12 & - & - & B & Y & 92 \\
\hline
\end{tabular}

Table 1. Effect of Geometrical Configuration on Peak Overpressure

Figures 2 shows typical high-speed images for Configuration three where two grids are positioned as shown Table 1. Figure 3 shows pressure-time traces for Configurations 1, 2 and 3 with peak overpressures gradually decreasing as also shown from Table 1. Configuration one where a turbulence grid is located at each station yielded the highest peak overpressure and fastest flame speed. Following ignition $(t=0)$ the flame front expands hemispherically until reaching the walls of the vessel and then propagates longitudinally downstream at a speed of around $4 \mathrm{~m} / \mathrm{s}$ before reaching the first grid at around $\mathrm{t}=5 \mathrm{~ms}$ (note the far right-hand black line in each image is a bolt holding the vessel together and not turbulence generator). There is only a slight increase in pressure as the flame front accelerates through the first grid (S1). The pressure starts to increase significantly as the flame approaches the second and/or third grid and peak just before the flame front crosses the obstacle.

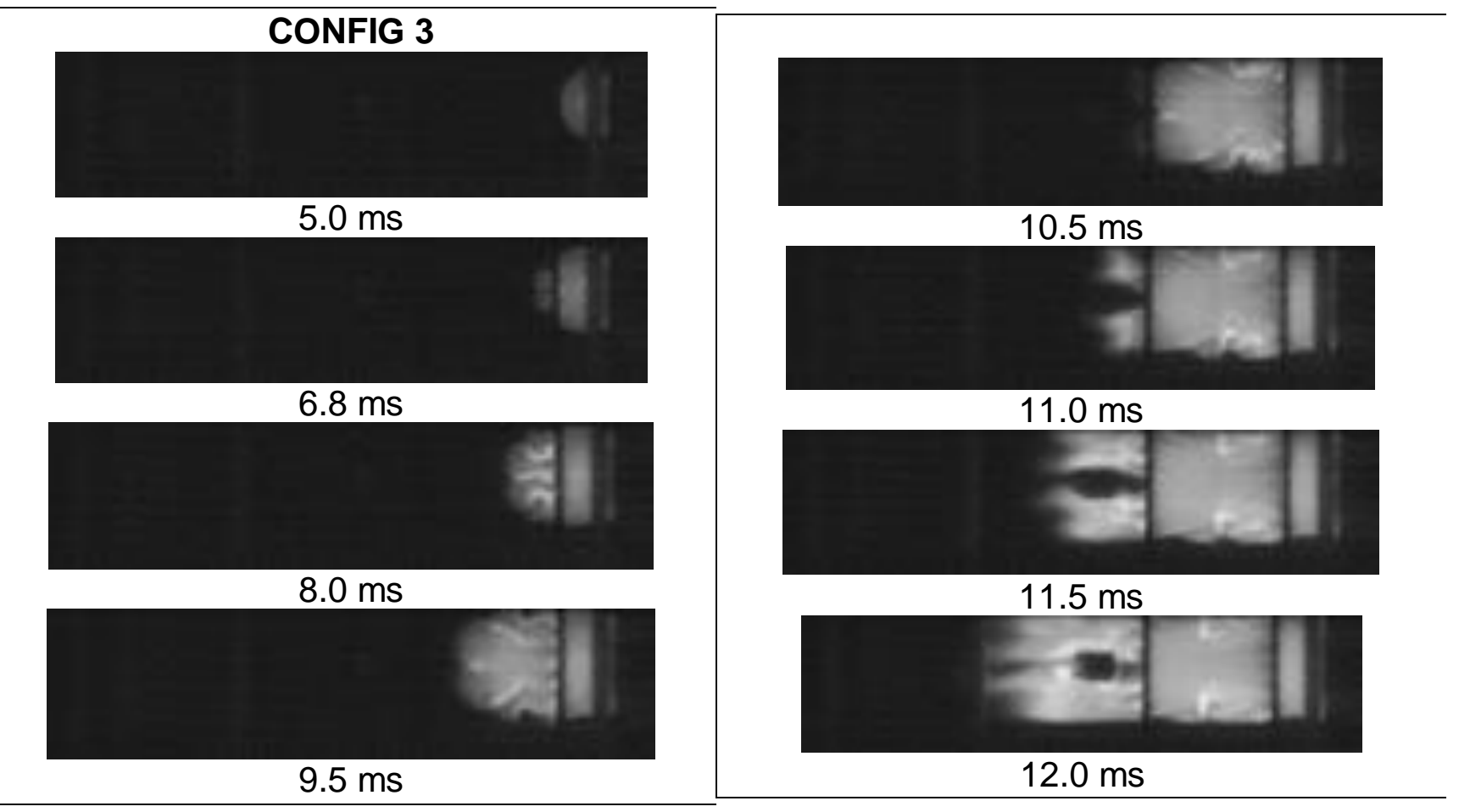


Details of other configurations are also given in Table 1. Configurations 5 and 6 clearly show that the location of the grid within the chamber is important. Using a single, identical grid results in a much higher overpressure id that grid is placed further downstream in the chamber. In Configuration 5 there has been significantly more expansion of hot gases when the flame front reaches the first grid when compared to Configuration 6 . This results in the flame propagating into a more turbulent flow-field, giving rise to a higher burning rate and a higher peak overpressure.

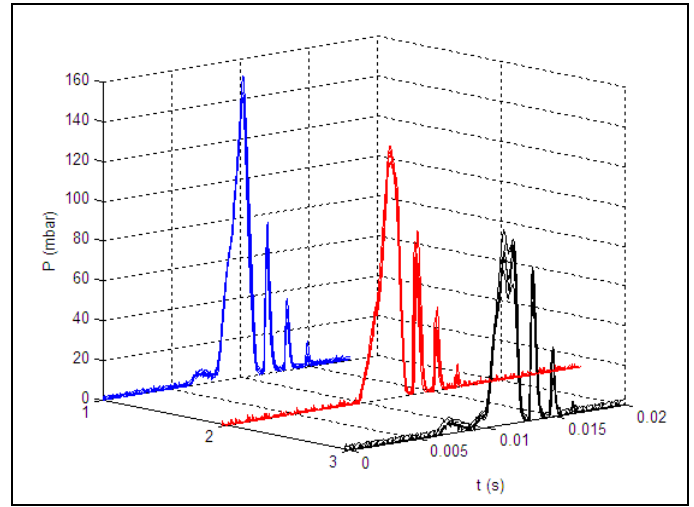

Fig. 2 Pressure- time traces for Configurations 1, 2 and 3.

\subsection{Flowfield Measurements}

Laser Doppler Velocimetry, LDV was used to measure the mean and rms velocities for the selected flames as well as for non-reacting cold-flow cases with similar flow conditions. The system used was a commercial PDPA system (TSI FSA 3500) with two channels utilising a Spectra Physics 2017, $7 \mathrm{~W}$ argon-ion laser. The central jet was seeded with 1 micron aluminium oxide particles, with results conditioned such that only data with a seed particle diameter less than 10 microns is used in the calculations, preventing spurious data points from agglomerated particles that do not follow the flow contaminating the results. Data was collected in the forward scatter mode at 30 degrees off axis, with typical mean data rates of 2$3 \mathrm{kHz}$ being achieved. For each location 10000 data points were taken to compute the mean and rms velocity, with all data being corrected for velocity bias.

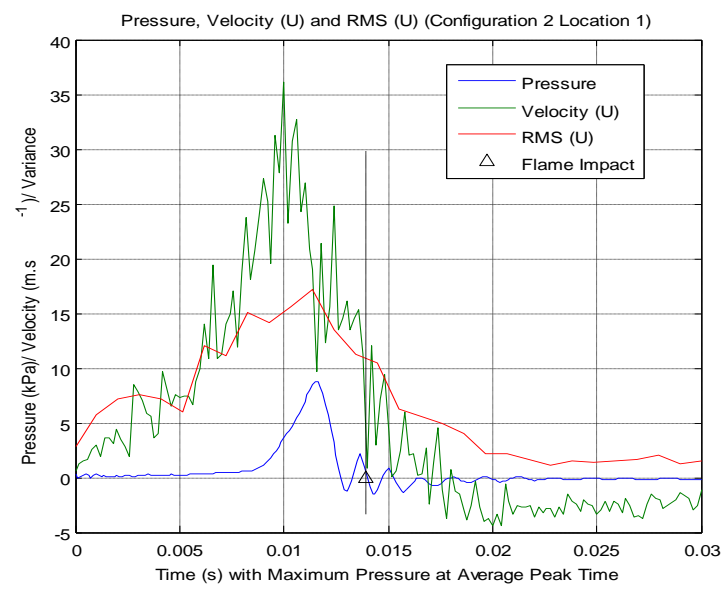

Fig. 3 Mean and rms velocity fluctuations as well a pressure- time traces measured for Configuration 2. 
Figure 3 shows a sample image of the mean velocity and rms fluctuations time traces along with the pressure. The vertical dashed line on this plot marks the time at which the flame crosses the LDV measurement location so velocities measured earlier are in non-reacting gases. These data are extremely useful for model validation..

\subsection{Laser Induced Fluorescence of $\mathrm{OH}$}

Laser induced Fluorescence from the hydroxyl radical, OH (LIF-OH) is performed using a dye pumped Nd-YAG laser. The exciting wavelength is $284 \mathrm{~nm} \mathrm{~nm}$ and LIF is collected at $310 \mathrm{~nm}$ on a CCD camera with $648 \times 595$ pixels. Three quartz windows, each $50 \mathrm{~mm}$ in diameter, have been located at (i) $50 \mathrm{~mm}$ downstream of the ABP, (ii) next to the obstacle, and (iii) $54 \mathrm{~mm}$ downstream of the centreline of the obstacle's axis. The imaged area is $28 \times 23 \mathrm{~mm}$. The timing is such that the LIF measurement is made when just when the flame front is crossing the imaging window. Therefore, the experiment is tedious in that each explosion event results in one $\mathrm{OH}$ image through one viewing window only.

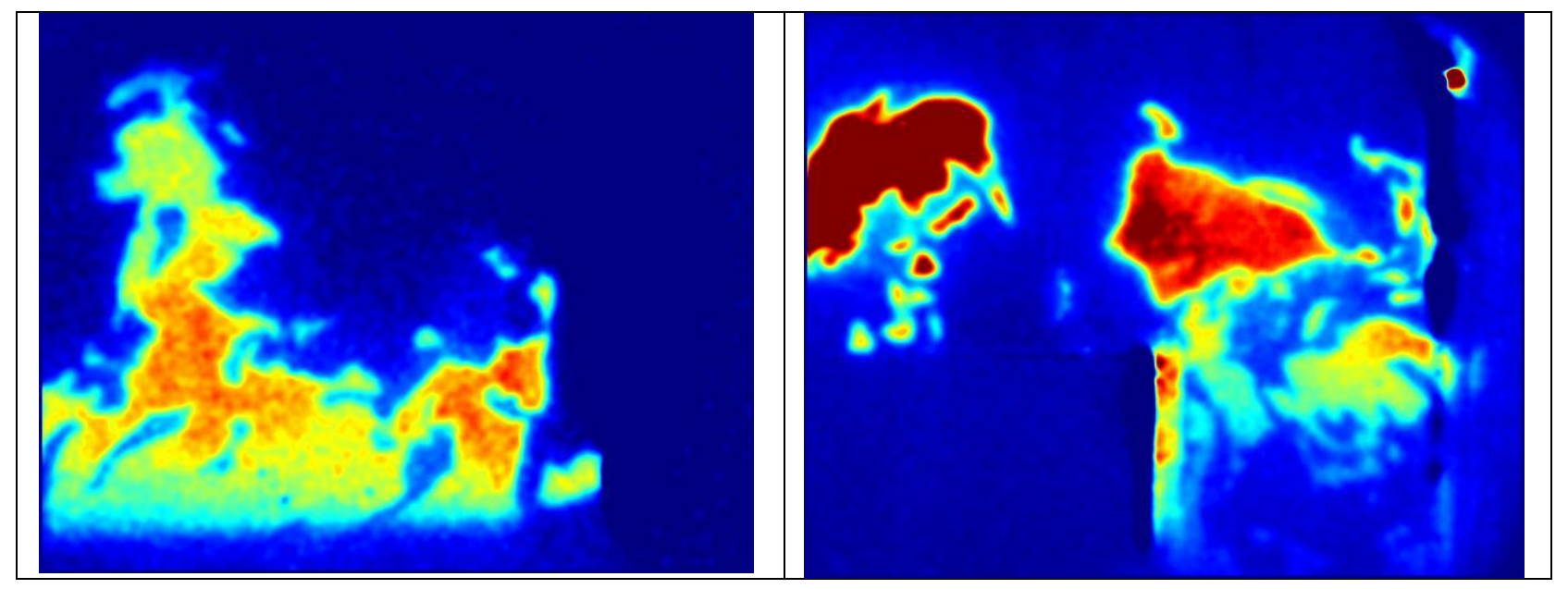

Fig. 4 LIF-OH images taken for Configuration 1 where three grids are used without the square obstacle (top) and with the square obstacle which appears on the lower left hand side of the image (bottom).

Figure 4 shows representative LIF images of $\mathrm{OH}$ for Configuration 1 collected in the channel near the obstacle. It is clear from these images that the grids distort and wrinkle it quite substantially. Further distortion is caused by the obstacle as shown from the lower image of Figure 4.

\section{Numerical}

Flow computations in this chamber as well in other similar configurations have been reported using both RANS and LES approaches $[1,2,14,15]$. Only LES calculations are addressed here given that this field is relatively and still evolving. Issues of subgrid scale modeling of both shear stresses and chemical reaction. Subgrid scale stresses are parameterized using either the Smagorinsky eddy viscosity model [32] or the Germano model [33]. The model coefficient is calculated from local, instantaneous flow conditions using the dynamic procedure for compressible flow of Moin et al. [34]. Subgrid scale turbulent fluxes are 
generally calculated using gradient transport assumptions for scalars that use the eddy viscosity and a turbulent Prandtl number.

Subgrid scale modeling of the mean reaction rate is more difficult. The filtered mean reaction rate term, $\overline{\dot{w}}_{c}$ is expressed in terms of the laminar burning velocity $u_{L}$ and the flame surface area per unit volume (flame surface density), $\Sigma$ as:

$$
\overline{\dot{w}_{c}}=\rho_{u} u_{L} \Sigma
$$

where $\rho_{u}$ is the unburned mixture density. Using the flamelet approach, $\Sigma$ may be formulated in terms of the reaction progress variable and the filter width, $\Delta$.

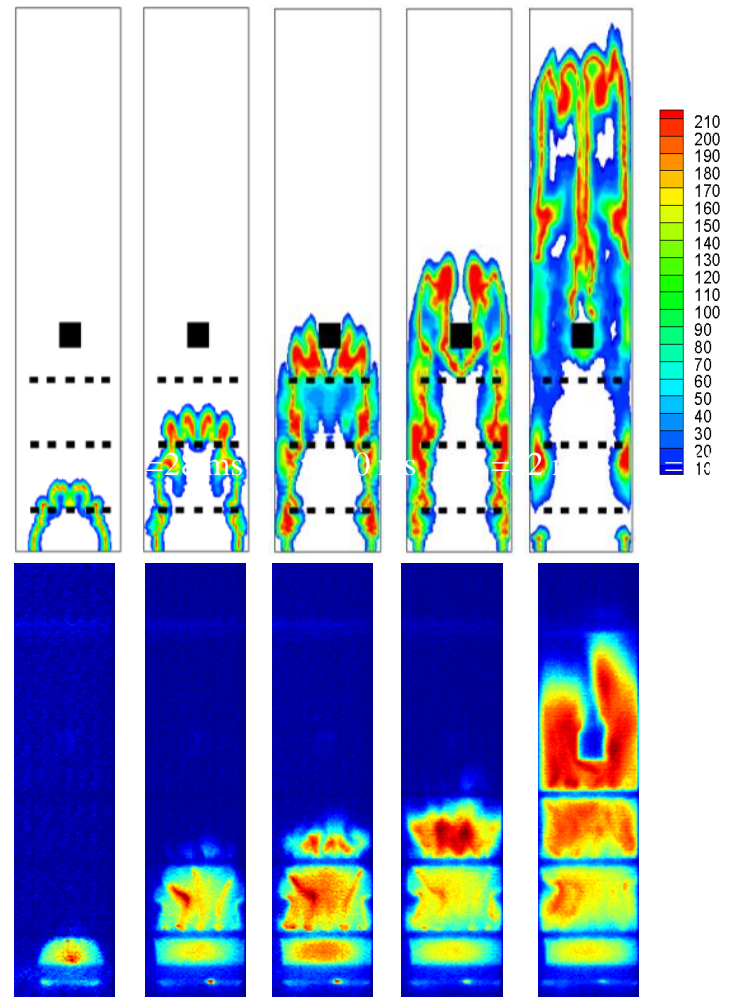

Fig. 5 High speed flame images (bottom) and LES calculations of the reaction progress variable (top) at about 6, 9.5, 10, 10.5 and $11 \mathrm{~ms}$ after ignition for Configuration 1.

Obtaining an accurate solution from LES simulations of combustion systems is non-trivial and depends on many numerical and modeling parameters. A good LES solution should be independent of both the grid size and the filter width. The choice of filter width is critical for LES as this determines how much of the energy spectrum is resolved. In a conceptual study of LES, Pope [35] hypotheses that good LES resolves about $80 \%$ of the energy spectrum and a good the solution may reach an intermediate asymptote when the filter width lies within the inertial sub-range. Moreover, the combustion model used should be independent of the filter width as well as the grid size. It should be acknowledged at this stage that LES is still evolving and a number of recent publications $[31,36]$ have discussed methodologies and approaches toward achieving grid-independent LES. 
Figure 5 shows a sample of LES calculations made for Configuration 1 with three grids and an obstacle. The figure compares the reaction progress variable computed at various times across the chamber with the flame images taken at similar or very close times using a high speed camera. Good agreement is generally obtained considering that flame moves very fast as it crosses the grids. Improvement could be made with respect to the simple combustion model used here and this is currently attempted through the use of advanced FSD approaches.

\section{General Discussion}

The following conclusions are now well-established as common amongst the various experimental chambers that have a relatively high L/D: (i) the overpressure increases with increasing blockage ratio of the obstacle, (ii) cylindrical obstacles yield the lowest increase in overpressure while obstacles with square cross sections yield the highest, (iii) the initial pressure increase occurs as the vent seal is being broken and higher overpressures are obtained with higher venting resistance, (iv) the peak overpressure occurs as the flame front is crossing the obstacle(s), (v) unburnt gas is trapped on the upstream as well as downstream flat faces of obstacles (such as flat plates or those with square cross sections) and this unburned gas is consumed later after the main flame leaves the chamber leading to subsequent oscillations in the pressure.

Other more recent findings obtained from the experimental chamber investigated at the University of Sydney include: (i) baffle plates or turbulence generating grids need to be judiciously designed and positioned in the chamber to increase turbulence levels. (ii) the location of the turbulence generating grids with respect to the main obstacle has an important effect on the flame structure because turbulence tends to decay very quickly do to heat release. (iii) LIF-OH imaging reveals significant distortion in the structure of the flame front as turbulence levels increase.

Green and co-workers have recently investigated flame propagation in chambers with L/D of about 0.235 which is much smaller than those studied here. The findings from these 'flatter' chambers appear to be controversial in that the peak overpressure is obtained with cylindrical obstacles rather those with square cross sections and the peak flame overpressure is obtained after the flame leaves the chamber. Such results are specific to chambers of low L/D where the residence time of the flame is very short and turbulence does not have time to develop as is the case in chambers with high L/D.

\section{Acknowledgments}

The authors is grateful to Prof. A.R.Masri for the LIF-OH images and the velocity data. Thanks also go to Dr S. Gubba for supporting the LES calculations.

\section{References}

1. Kirkpatrick, M.P., Armfield, S.W., Masri, A.R., and Ibrahim, S.S., Flow, Turbulence and Combustion 70(1):1-19 (2003). 
2. Masri, A.R., Ibrahim, S.S., and Cadwallader, B.J., Experimental Thermal and Fluid Science, 30:687-702 (2006).

3. Prasad, R.O.S. and Gore, J.P., Combust. Flame 116:1-14 (1999).

4. Veynante, D., Piana, J., Duclos, J.M., and Martel, C., Proc. Combust. Inst. 26:413-420 (1996).

5. Patel, S.N.D.H., Jarvis, S., Ibrahim, S.S., and Hargrave, G.W., Proc. Combust. Inst. 29:1849-1854 (2002).

6. Bray, K.N.C., Proc. Combust. Inst. 26:1-26 (1996).

7. Hjertager, B. H., Fuhre, K., and Bjorkhaug, M., Combust. Sci. Technol. 62:239-256 (1988).

8. Moen, I. O., Lee, H. S., Hjertager, B. H., Fuhre, K., and Eckhoff, R. K. Combust. Flame. 47: 31-52 (1982)

9. Bradley, D., Cresswell, T. M., Puttock, J. S., Combust. Flame. 124:551-559 (2001)

10. Masri, A.R., Ibrahim, S.S., Nezhat, N and Green, A.R., Experimental Thermal and Fluid Science Journal 21:109-116 (2000).

11. Ibrahim, S.S., and Masri, A.R., Journal of Loss Prevention in the Process Industries 14:213-221 (2001).

12. Starke, R. and Roth, P., Combust. Flame. 66: 249-259 (1986)

13. Starke, R. and Roth, P., Combust. Flame. 75: 111-121 (1989).

14. Fairweather, M., Ibrahim, S. S., Jaggers, H. and Walker, D. G. Proc. Combust. Inst. 26:365-371 (1996)

15. Fairweather, M., Hargrave, G. K., Ibrahim, S. S., and Walker, D. G. 'Combust. Flame. 116:504-518 (1999)

16. Phylaktou, H. and Andrews, G. E., Combust. Flame. 85: 363-379 (1991)

17. Alexiou, A., Andrews, G. E., and Phylaktou, H., Journal of Loss Prevention in the Process Industries 9:351-356 (1996).

18. Moen, I. O., Donato, M., Knystautas, R. and Lee, J. H., Combust. Flame 39:21-32 (1980).

19. Lindstedt, R. P and Sakthitharan, V., Combust. Flame. 114: 469-483 (1998)

20. Catlin, C. A., Lindstedt, R. P., Combust. Flame 85: 427-439 (1991)

21. Green, A.R., Park, D.J., and Nehzat, N., 'Experimental Studies of Flame Propagation and Pressure Rise in a 1:54 Scale Coal Mine Model Using Different Wall Roughness', $5^{\text {th }}$ AsiaOceania Symposium on Fire Science and Technology, Newcastle, Australia 2001. 
Proceeding of the $14^{\text {th }}$ AMME Conference, $25-27$ May 2010

22. Bradley, D., Proc. Combust. Inst. 24:247-262 (1992).

23. Charlette, F., Meneveau, C., and Veynante, D., Combust. Flame 131:181-197 (2002).

24. Fureby, C., Proc. Combust. Inst. 30:593-601 (2005).

25. Knikker, R., Veynante, D. and Meneveau, C, Proc. Combust. Inst. 29:2105-2111 (2002).

26. Mathew, J., Proc. Combust. Inst. 29:1995-2000 (2002).

27. Pitsch, H., De Lageneste, D., Proc. Combust. Inst. 29:2001-2008 (2002).

28. Branley N. and Jones W.P., Combust. and Flame 127:1914-1934 (2001).

29. Kempf A., Sadiki A. and Janicka J., Proc. Combust. Inst. 29:1979-1985 (2002).

30. Pitsch, H., Proc. Combust. Inst. 29:1971-1978 (2002).

31. Janicka, J. and Sadiki, A., Proc. Combust. Inst. 30:537-547 (2005).

32. Smagorinsky, J. Monthly Weather Review 91:99-164 (1963).

33. Germano, M., Piomelli, U., Moin, P., and Cabot, W.H., Phys. Fluids A3(7):1760-1765 (1991).

34. Moin, P., Squires. K., Cabot, W., and Lee, S., Phys Fluids A 3:2746--2757 (1991).

35. Pope, S.B., New Journal of Physics, 6(2004) 35.

36. Selle, L., Lartigue, G., Poinsot, T., Koch, R., Schilmacher, K.-U., Krebs, W., Prade, B., 